\title{
perifèria
}

Número 16, junio 2012

revistes.uab.cat/periferia - www.periferia.name

\section{Validació i interpretació científica. Tres propostes d'actuació: Fleck, Pike i Agar.}

\author{
Rafel Argemí i Baldich \\ Universitat Autònoma de Barcelona ${ }^{1}$
}

\begin{abstract}
Resum
L'article té com a fonament I'anàlisi dels plantejament teòrics de Fleck (amb els conceptes de col-lectiu de pensament i estils de pensament), Pike, (amb els conceptes d'èmic i ètic) i Agar (amb els plantejaments de l'estranyament i les quiebras), en relació a la validació de les conclusions i dels canvis de posicionament que es produeixen en l'investigador durant el transcurs del treball de camp antropològic. Per tal de mostrar el procés de validació que es du a terme en el treball de camp, basaré I'anàlisi dels diferents plantejaments teòrics en diferents exemples etnogràfics (Bohannan, Wolcott, i Malighetti).
\end{abstract}

Paraules clau: Validació científica, treball de camp, epistemologia.

\begin{abstract}
The paper analyzes the Fleck's, Pike's and Agar's theoretical basis related to the validation of the resultants and changes in the researcher's ideas during the anthropological fieldwork process. Firstly, Fleck explains these changes through the concepts of thought collectives and thought styles. Secondly, Pike focuses his analyses on the concepts of emic and etic; and thirdly, Agar develops the estrangement approach and the breakdowns. In order to show the validation process that takes place in the anthropological fieldwork, we expose and analyses different ethnographic examples such as Bohannan, Wolcott, and Malighetti.
\end{abstract}

Keywords: Scientific validation, fieldwork, epistemology.

El present article ha estat escrit en base als dubtes i reflexions sobre el treball de camp, que se'm han plantejat a partir de cursar l'assignatura "Orientacions metodològiques en antropologia" impartida per la Dra. Aurora González Echevarría. Considero important el plantejament de diferents qüestionaments en el

\footnotetext{
${ }^{1}$ Enviar correspondència a: Rafel Argemí i Baldich, rafelargemi@gmail.com

2 Assignatura impartida en el marc del Màster en Investigació etnogràfica, teoria antropològica $i$ relacions interculturals de la Universitat Autònoma de Barcelona.
} 


\section{perifèria}

Número 16, junio 2012

revistes.uab.cat/periferia - www.periferia.name

transcurs de definició i execució del treball de camp antropològic, i en el meu cas, aquests interrogants cada vegada se'm plantegen més intensament, degut a que em trobo en la fase de plantejament del projecte d'investigació, la qual cosa implica la definició de I'objecte d'estudi, els objectius, les hipòtesis... En aquest sentit, el procés d'estranyament que hauré de fer durant la definició i posterior execució del treball de camp és considerable, degut a que analitzo el col-lectiu del professorat i alhora en formo part. Per aquest motiu, en primer lloc hauré de desenvolupar un procés d'estranyament vers la societat circumdant, i posteriorment, hauré de conduir-lo vers el col-lectiu a investigar, del qual -com ja he apuntat- també en formo part. En aquest moment delicat de la recerca, és important considerar el suggeriment de San Román (2009) quan especifica que hem d'evitar el risc de considerar culturalment properes qualsevulla situacions i persones de la societat de l'etnògraf, així com també, hem de fer un esforç encara major per tal d'arribar a conèixer la diversitat cultural interna.

Els debats metodològics al voltant de la validació han estat una constant de I'antropologia durant la seva història. A mitjans segle XX es produí dins de l'antropologia cultural un moviment dirigit a fer més rigorosos els criteris de descripció i anàlisi etnogràfics (Harris 2005 [1968]: 491). A finals de la dècada de 1950 es produí una revolució metodològica encapçalada per Jarvie a partir de les tesis de Popper. Segons González Echevarría (2006: 1-2), es tractà d'una efímera revolució metodològica contra el treball de camp -o més exactament, contra la seva escassa productivitat teòrica- i en pro a l'exigència de corroboració addicional per les explicacions generals. Així, i seguint González Echevarría (2006: 3), I'èmfasi en el treball de camp no comença amb les hipòtesis sinó amb les preguntes, $i$ l'èmfasi en el mateix treball de camp, no acaba amb les explicacions, sinó amb les interpretacions; fet que no ens allibera de la tasca fonamental de validar, fins on es puguin, les conclusions que extraiem.

Tot i el pas dels anys, la validació encara continua essent controvertida dins la disciplina antropològica. Diversos autors (Hammersley i Atkinson 1994 [1983]; San Román 1984 i 2009; Roigé, Estrada, i Beltrán 1999; Eisenhart 2001; entre d’altres) 


\section{perifèria}

Número 16, junio 2012

revistes.uab.cat/periferia - www.periferia.name

sostenen que la validació encara és una noció que en etnografia té un paper incert i moltes vegades, qüestionat.

Tenint en compte aquests debats, el present article pretén mostrar al lector diferents exemples de com dins el treball de camp els autors han fet front als canvis de plantejament que els han anat sorgint. Per aconseguir-ho, l'article es construeix entrellaçant dos eixos: a) plantejaments teòrics, i b) exemples etnogràfics.

En aquest sentit, es recullen els plantejaments teòrics sobre el canvi en el treball de camp proposat per tres autors diferents: Ludwik Fleck (1986 [1935]), amb els conceptes de collectiu de pensament i estils de pensament; Kenneth Pike (1971 [1954]), amb els conceptes d'èmic i ètic; i Michael Agar (2008 [1982]), amb el plantejament de l'estranyament i les ruptures o quiebras. Cadascun d'aquests plantejaments teòrics es presenta i s'analitza tot incorporant exemples etnogràfics que il-lustren i relaten en profunditat el procés d'investigació dut a terme per l'investigador, destacant els dubtes, els interrogants...

Els exemples etnogràfics corresponen al treball de camp de: Laura Bohannan (1993 [1966]), Shakespeare in the bush, per al plantejament teòric de Fleck; Harry Wolcott (2004 [1966]), A kwakiutl village and school, per al plantejament teòric de Pike; i Roberto Malighetti (2004), Il Quilombo di Frechal, per al plantejament teòric d'Agar.

\section{L'epistemologia de Fleck, estils de pensament i col-lectius de pensament}

Els trets fonamentals del pensament epistemològic de Ludwik Fleck es desenvolupen principalment a partir dels conceptes d'estils de pensament i de col·lectius de pensament (González Echevarría 2003).

El primer concepte, l'estil de pensament, té a veure amb que el treball dels científics es caracteritzen per una tradició d'assumpcions compartides, que a la 


\section{perifèria}

Número 16, junio 2012

revistes.uab.cat/periferia - www.periferia.name

vegada defineixen quines qüestions són les significatives i quines prefiguren les respostes apropiades (Atienza, et. al. 1994: 245). Així mateix, ambdós conceptes s'entrelliguen, degut a que l'estil de pensament està conformat per les propostes sobre les quals el col/lectiu de pensament construeix el seu edifici teòric (Fleck 1986 [1935]: 23). El segon concepte, el col-lectiu de pensament, és considerat com la unitat social de la comunitat de científics d'un camp determinat (1986 [1935]: 23), i per tant, no és la simple suma dels científics que la integren. Així doncs, cada estil de pensament neix d'un col-lectiu de pensament (Atienza, et. al. 1994: 246), i aquest té un caràcter eminentment col·lectiu i globalitzador (González Echevarría 2003: 247).

En el cas etnogràfic proposat per Laura Bohannan, tot just abans de partir cap al camp, la investigadora prengué part d'una conversa on es parlava de si Shakespeare era o no comprensible pels nord-americans. Ella, a partir d'un estil de pensament sostingut per un determinat col-lectiu humà (Helo 1989: 184), afirmà que no solament Shakespeare era comprensible pels nord-americans, sinó que aquest també ho era per tota la naturalesa humana. L'antropologia nord-americana del moment, hipotetitzava una naturalesa, i per tant, una capacitat de comprensió humana universals. Més endavant, una vegada ja inserida en el camp, se li presentà I'oportunitat de demostrar la universalitat de la comprensió de l'obra (Bohannan 1993 [1966]).

Per tal d'exemplificar la proposta de Fleck mitjançant la narració de Bohannan, és important centrar la nostra atenció en el moment del treball de camp, on l'autora explica Hàmlet als Tiv.

Per una banda, remarcar que l'autora i els Tiv pertanyen a dos col-lectius de pensament diferents, fet que també comporta estils de pensament diferenciats: ella prové del món occidental, i en particular de la comunitat científica d'antropòlegs nord-americans, i ells provenen de la comunitat dels Tiv de I'Àfrica Occidental. La primera es caracteritza per tenir una tradició de transmissió cultural principalment mitjançant textos escrits, els quals són publicats en llibres i revistes especialitzats. Els segons es caracteritzen per ser un poble d'agricultors de subsistència de I'Àfrica 


\section{perifèria}

Número 16, junio 2012

revistes.uab.cat/periferia - www.periferia.name

Occidental (Bohannon i Skoggard 1997), amb una transmissió cultural fonamentalment basada en la narració de contes orals.

Per altra banda, destacar, que en el moment en que l'autora explica Hàmlet, es posen de manifest com a mínim tres estils de pensament diferenciats: en primer Iloc, el del col-lectiu de pensament exotèric de l'època de Shakespeare (principis segle XVII); en segon lloc, el del col-lectiu de pensament esotèric de I'antropologia nord-americana del moment (dècada de 1960); i en tercer lloc, el del col-lectiu exotèric dels Tiv.

Finalment, i a partir dels diferents estils i collectius de pensament que es posen de manifest, es desenvolupa la narració del treball de camp proposat.

Estaba segura de que Hamlet tenía una sola interpretación posible, y de que ésta era universalmente obvia (1993 [1966]: 84). [Així que, quan els Tiv demanaren a Laura Bohannan que els expliqués el llibre que estava llegint, ella] asentí, dándome cuenta de que allí estaba mi oportunidad de demostrar que Hamlet era universalmente comprensible (1993 [1966]: 85).

En relació a l'estil de pensament i el col-lectiu de pensament, González Echevarría (2003: 244) es pregunta, com es produeix el canvi, si l'estil de pensament tendeix a fer-se tant compacte? La resposta recau en el fet de que, tot i que el científic pertany a un col-lectiu de pensament concret (col-lectiu esotèric), a més a més, també forma part del col-lectiu general de la vida diària (col-lectiu exotèric). D'altra banda, el científic també és membre d'altres col-lectius de pensament científics i no científics. I és en tots aquests col-lectius on es plantegen estímuls per a la transformació dels estils de pensament.

Tot i que tal com hem dit anteriorment, I'autora forma part del col-lectiu de pensament científic dels antropòlegs nord-americans (col-lectiu esotèric), quan s'insereix en el camp, també entra a formar part del col-lectiu de pensament dels Tiv (col-lectiu exotèric), amb els que comparteix la vida, i per tant, part de les seves maneres de pensar. No obstant, en iniciar l'explicació de Hàmlet, I'autora l'explicà a partir del col-lectiu de pensament de l'època de Shakespeare (col-lectiu 


\section{perifèria \\ Número 16, junio 2012 \\ revistes.uab.cat/periferia - www.periferia.name}

exotèric).

«Ayer no, ayer no, sino hace mucho tiempo, ocurrió una cosa. Una noche tres hombres estaban de vigías en las afueras del poblado del gran jefe, cuando de repente vieron que se les acercaba el que había sido su anterior jefe».

«¿Por qué no era ya su jefe?»

«Había muerto», expliqué, «es por eso por lo que se asustaron y se preocuparon al verle».

«Imposible», comenzó uno de los ancianos, pasando la pipa a su vecino, quien lo interrumpió. «Por supuesto que no era el jefe muerto.

Era un presagio enviado por un brujo» (1993 [1966]: 85).

En començar a explicar la història als Tiv, I'autora percep la diferència existent entre l'estil de pensament del col-lectiu exotèric històric-europeu, i l'estil de pensament del col·lectiu exotèric dels Tiv. És a dir, a començaments segle XVII, època en que Shakespeare escrigué Hàmlet, l'existència dels fantasmes era àmpliament donada per bona a Europa, i Bohannan -la qual pertany, entre d'altres, a col-lectius exotèrics que coneixen l'existència històrica de la creença en fantasmes- explicà la història en base al col-lectiu de pensament de l'època de Shakespeare. Per contra, els Tiv formen part d'un col-lectiu exotèric on l'existència dels fantasmes és desconeguda. En el moment de començar a explicar la història, ambdós col-lectius de pensament entenen de forma diferenciada allò escrit. Així, Hàmlet es troba interpretat i re-interpretat contínuament segons el col-lectiu de pensament al que es pertany i els estils de pensaments característics de cadascú.

Els estils de pensament tenen com a característica el canvi continuat de significat dins de la investigació. D’aquesta manera, seguint González Echevarría (2003: 243), el que buscarà l'investigador serà la resistència de les constatacions creades a partir de les connexions passives (experiència), contra l'arbitrarietat de les determinacions creades a partir de les connexions actives (supòsits epistemològics 


\section{perifèria}

Número 16, junio 2012

revistes.uab.cat/periferia - www.periferia.name

propis de l'estil de pensament del col-lectiu científic al qual es pertany).

En el fragment que es presenta a continuació, es perceben les resistències entre les constatacions del col-lectiu exotèric de l'època de Shakespeare i les constatacions del col-lectiu exotèric dels Tiv. Mentre que en el primer, els fantasmes són essers existents dins les assumpcions compartides d'aquesta comunitat de pensament; els segons ho fan a partir de les seves pròpies, les pertanyents al col-lectiu exotèric del que formen part, on -dissortadament per l'autora-, el concepte de fantasma és desconegut.

«Esa noche Hamlet se quedó vigilando junto a los tres que había visto a su difunto padre. El jefe muerto apareció de nuevo, y aunque los demás tuvieron miedo, Hamlet le siguió a un lugar aparte. Cuando estuvieron solos, el padre muerto habló».

«iLos presagios no hablan!» El anciano era tajante.

«El difunto padre de Hamlet no era un presagio. Al verlo podría parecer que era un presagio, pero no lo era». Mi audiencia parecía estar tan confusa como lo estaba yo. «Era en verdad el padre muerto de Hamlet, lo que nosotros llamamos un 'fantasma'». Tuve que usar la palabra inglesa, puesto que estas gentes, a diferencia de muchas de las tribus vecinas, no creían en la supervivencia de ningún aspecto individualizado de la personalidad después de la muerte.

«¿Qué es un 'fantasma'? ¿Un presagio?»

«No, un 'fantasma' es alguien que ha muerto, pero que anda vagando y es capaz de hablar, y la gente lo puede ver y oír, aunque no tocarlo».

Ellos replicaron. «A los zombis se les puede tocar»

«iNo, no! No se trataba de un cadáver que los brujos hubieran animado para sacrificarlo y comérselo. Al padre muerto de Hamlet no lo hacía andar nadie. Andaba por sí mismo». 


\section{perifèria}

Número 16, junio 2012

revistes.uab.cat/periferia - www.periferia.name

«Los muertos no andan», protestó mi audiencia como un solo hombre.

Yo trataba de llegar a un compromiso. «Un 'fantasma' es la sombra del muerto».

Pero de nuevo objetaron. «Los muertos no tienen sombra»... (1993 [1966]: 87-88).

El fragment posa de manifest les diferències entre estils de pensament i col-lectius de pensament, així com, de forma preeminent, exposa les resistències entre les connexions passives i actives. Més ben dit, en el relat es posen de manifest: a) l'arbitrarietat de les determinacions creades a partir de les connexions actives, en la manera com es concep el món dels esperits: els fantasmes i les aparicions d'aquests; b) les resistències de les constatacions creades a partir de les connexions passives, en la manera com aquests també interpreten el món dels esperits: els zombis; c) la confluència entre les connexions passives i actives, i com cadascuna d'elles cedeix lloc als coneixements aportats per l'altre, per tal d'arribar a una posició d'enteniment. Així, i a mode de resum, veiem que partim de dos maneres de concebre el món dels esperits diametralment oposades, i que a partir d'un procés de negociació dels significats, de mica en mica els posicionaments es van acostant.

«Es una historia muy buena», añadió el jefe, «y la has contado con muy pocos errores» [...] Envolviéndose en su raída toga, el anciano concluyó: «Alguna vez has de contarnos más historias de tu país. Nosotros, que ya somos ancianos, te instruiremos sobre su verdadero significado, de modo que cuando vuelvas a tu tierra tus mayores vean que no has estado sentada en medio de la selva, sino entre gente que sabe cosas y que te ha enseñado sabiduría» (1993 [1966]: 93).

Finalment, tot i el xoc entre l'estil de pensament exotèric històric-europeu i l'estil de pensament exotèric Tiv, i després del procés de negociació dut a terme, les posicions s'han acostat, fent comprensible allò inicialment incomprensible, i 


\section{perifèria}

Número 16, junio 2012

revistes.uab.cat/periferia - www.periferia.name

canviant el posicionament inicial de l'autora, quan defensava que Shakespeare era universalment comprensible -en base al collectiu de pensament esotèric de I'antropologia nord-americana del moment, que hipotetitzava una naturalesa, i per tant, una capacitat de comprensió humana universal-. A partir del canvi produït, acabem la proposta formulada per Fleck, i compartint, tal com el propi Ludwik Fleck sosté, que tot descobriment empíric solament pot concebre's com un desenvolupament o com una transformació de l'estil de pensament (Fleck 1986 [1935]: 138).

\section{La dicotomia dels enfocaments èmic/ètic}

Previ a abordar la dicotomia èmic/ètic formulada per Pike, és important fer esment a les desviacions que aquests termes han tingut al llarg dels anys, degut principalment a l'ambigüitat amb que Pike els caracteritzà, a partir de parells d'oposicions: des de dintre/des de fora, o inicial/final (González Echevarría 2009b). Amb tot, la desviació més significativa recau en la re-interpretació que en feu Marvin Harris, quan considerà que:

Las proposiciones emic se refieren a sistemas lógico-empíricos cuyas distinciones fonémicas o "cosas" están hechas de contrastes y discriminaciones que los actores mismos consideran significativas, con sentido, reales, verdaderas o de algún otro modo apropiadas; [és a dir, el punt de vista dels nadius] (2005 [1968]: 493).

Las proposiciones etic dependen de distinciones fenoménicas consideradas adecuadas por la comunidad de observadores científicos; [és a dir, el punt de vista de l'etnògraf] (2005 [1968]: 497).

Aquesta contraposició d'enfocaments èmic/ètic, o punt de vista nadiu/punt de vista etnògraf o científic, actualment està defenestrada a nivell científic, però a nivell empíric la seva utilització encara resulta molt corrent.

En aquest sentit, el recent treball de González Echevarría (2009b) aborda 


\section{perifèria}

Número 16, junio 2012

revistes.uab.cat/periferia - www.periferia.name

abastament l'ambigüitat en la utilització dels termes èmic i ètic, i novament conceptualitza, a partir del treball de Pike (1971 [1954]) els enfocaments ètic i èmic.

Així, l'enfocament ètic és entès per l'autora com a preliminar i hipotètic, com l'equipatge conceptual (termes, classificacions, tipologies...) que permet l'accés al sistema, com el punt de partença d'un anàlisi que es va refinant progressivament fins que la presentació final es fa en unitats èmic, pertanyents a la cultura estudiada (2009a i 2009b). Mentre que I'enfocament èmic tracta d'adonar-nos de les estructures descobertes, a les que s'hi arriba mitjançant les verbalitzacions dels nadius però també, i sobre tot, mitjançant l'observació de reaccions provocades intencionadament i de l'observació dels comportaments significatius (2009a).

Si analitzem la monografia de Wolcott (2004 [1966]) amb les ulleres que ens proporciona Pike a partir de la proposta sobre la dicotomia d'enfocaments èmic i ètic, aquesta pren una nova dimensió. En ella es mostren diferents aspectes, percepcions, classificacions, i sobretot, canvis duts a terme durant el transcurs de la seva realització. No és el producte final, sinó que és el procés del producte, la vivència de l'autor en aquell precís moment. Com entrà carregat amb l'equipatge preliminar (enfocament ètic), i com en sortí amb un equipatge diferent (enfocament èmic). Amb tot, el contacte amb la població objecte d'estudi es prolongà amb el temps, i el canvi respecte el posicionament inicial de l'autor encara resulta més agut.

En un article de reflexió posterior al treball de camp entre els Kwakiutl, Wolcott (2005 [1974]), recorda les experiències que havia tingut durant la realització d'aquest. En ell també reflexiona sobre I'experiència prèvia com a alumne en una escola; i sobre les intencions que tenia abans de marxar a fer el treball de camp, amb la doble condició de mestre i etnògraf.

L'experiència prèvia és una part fonamental de l'equipatge conceptual amb que I'autor arriba al camp, la qual podem considerar com a punt de partença de l'investigador. Dit d'altra manera, aquest equipatge conceptual primari, podem 


\section{perifèria}

Número 16, junio 2012

revistes.uab.cat/periferia - www.periferia.name

considerar-lo, com l'enfocament ètic més iniciàtic, àdhuc, enfocament ètic inconscient.

En mi caso, la experiencia antes de llegar a Blackfish se había visto limitada a los confines de una situación de clase media de la que yo era en gran medida parte y producto. [...] Nunca había encontrado maestros o alumnos con los que no compartiera expectativas relativamente semejantes respecto a conductas, valores y actitudes (2005 [1974]: 252).

Per altra banda, tot i que l'experiència escolar de l'autor és part de l'enfocament ètic més primerenc, no hem d'oblidar, que com a científic, també arrossegava tot un altre equipatge preliminar, aquest formava part de l'equipatge de caire acadèmic. Els pre-conceptes, les percepcions, i les intuïcions inicials, també podem considerar-les com a enfocament ètic.

Como maestro, tenía la responsabilidad de llevar una escuela de una única aula que recibía a todos los niños residentes en el poblado de entre seis y dieciséis años. Como etnógrafo, tenía la intención de identificar y mostrar la influencia de las barreras culturales en el trabajo escolar, una forma de estudiar por qué es frecuente que los alumnos indios hayan parecido ser refractarios a los esfuerzos de la educación formal que despliegan las escuelas (2005 [1974]: 243).

Després de l'estada en el camp, l'equipatge conceptual de l'autor fou modificat. La modificació vingué donada per diferents processos que posteriorment abordarem, però el fet més important, és que Wolcott adquirí una nova visió del fenomen investigat. Aquest nou enfocament de l'autor és el que considerem com a enfocament èmic, el qual ens permetrà adonar-nos de les estructures descobertes dins del sistema investigat.

En relació a l'etnografia presentada, l'autor manifesta un canvi important alhora de concebre l'escola, i concretament, l'escola índia. Altrament, la direcció vers on 


\section{perifèria}

Número 16, junio 2012

revistes.uab.cat/periferia - www.periferia.name

enfocar els seus esforços també fou variada. Ara ja no parla en termes de «per què és freqüent que els alumnes indis semblen ser refractaris als esforços de l'educació formal»; sinó que parla en termes de comprensió, coneixement local, fer conscients als alumnes dels seus propis coneixements...

Se mi trovassi oggi di fronte alla classe Kwakiutl che ebbi nel 1962, dedicherei il mio maggior sforzo intellettuale a cercare di individuare quello che i bambini già sanno (individualmente e collettivamente) e a scoprire come quelle conoscenza erano state acquiste, il mio maggiore sforzo fisico servirebbe invece a far tirare avanti la scuola. La mia strategia sarebbe quella di imparare da e sui miei studenti e, nel farlo, cercharei di renderli autoconsapevoli dei processi della conoscenza ${ }^{3}$ (2004 [1966]: 224).

Aquests canvis substancials en el posicionament de Wolcott durant el treball de camp entre els Kwakiutl (el pas d'un posicionament ètic a un posicionament èmic), no és producte de l'atzar, sinó que és el resultat d'un procés continuat de relació, comprensió i enteniment amb la població objecte d'estudi.

En el relat posterior al treball de camp, Wolcott exposa de quina manera tractava de dur a terme el procés d'ensenyança-aprenentatge dels infants de Blackfish. Després d'alguns intents fallits en aquest procés, d'observar les reaccions dels alumnes, i de les recriminacions dels propis alumnes, l'autor cercà un mètode que no li comportés des de l'inici un fracàs contundent.

Durante el año que estuve de maestro en la escuela india de Blackfish siempre traté de encontrar una perspectiva alternativa de enseñanza, una perspectiva que me permitiera un programa educativo sin que

3 "Si avui dia em trobés enfront a la classe Kwakiutl que tenia el 1962, dedicaria els meus esforços intel-lectuals, de forma majoritària, a provar de saber allò que els nens ja saben (individual $i$ col-lectivament) i a descobrir com aquells coneixements havien estat adquirits; el meu major esforç físic serviria, en canvi, per dur endavant l'escola. La meva estratègia seria aquella d'aprendre de, i sobre, els meus estudiants, i en fer-ho, provaria de fer-los conscients dels processos de coneixement." 


\section{perifèria}

Número 16, junio 2012

revistes.uab.cat/periferia - www.periferia.name

conllevara frustración personal en caso de fracaso y sin que alentara una atmósfera de hostilidad donde yo había intentado crear una atmósfera de ayuda (2005 [1974]: 253).

El coneixement i la comprensió així com l'enteniment dels alumnes, conduïren més d'una vegada, a situacions inesperades, les quals, de mica en mica anaren configurant el posterior canvi d'enfocament de l'autor, de l'ètic a l'èmic. Així, els intents de socialització del professor per part dels alumnes, responen a la demanda d'un canvi d'actitud. Aquest intent de socialització, tot i ser una reacció intencionada dirigida al canvi, també està adreçada a mostrar comportaments i hàbits significatius pels alumnes Kwakiutl, els quals fan adonar a l'autor de les estructures de la societat en qüestió, i finalment, fer el pas d'un posicionament a I'altre.

I bambini si davano da fare per socializzare me cosi como io cercavo di socializzare loro. [...] I ragazzi mi insegnavano a non parlare tanto in classe, a non dare tanti ordini, a non interferire con le loro relazoni di gruppo, a non forzarli a lavorare troppo intensamente e a fare buon viso a qualsiasi situazione. Non lasciavano che mi allontanassi molto da quella che consideravano la routine del lavoro in classe. Occasionalmente una discussione li poteva interessare, ma di solito un cambiamento nella routine provocava commenti del tipo «Non siamo venuti a scuola perquesto, siamo venuti per fare i nostri compiti» ${ }^{4}(2004$ [1966]: 156).

\footnotetext{
4 "Els nens volien socialitzar-me a mi tal com jo tractava de socialitzar-los a ells. [...] Els nois m'ensenyaven a no parlar tant a classe, a no donar tantes ordres, a no interferir en les seves relacions de grup, a no forçar-los a treballar massa intensament i a fer bona cara a qualsevol situació. No deixaven que m'allunyés massa d'aquelles que consideraven haurien de ser les rutines escolars. Ocasionalment una discussió els podia interessar, però de cop i volta, un canvi en les rutines provocava comentaris del tipus: «no hem vingut a l'escola per això, hem vingut a fer els nostres deures".
} 


\section{perifèria}

Número 16, junio 2012

revistes.uab.cat/periferia - www.periferia.name

Per tant, considerem que tot i que aparentment es produeix un canvi d'enfocament, passant d'un enfocament ètic a un enfocament èmic, aquest pas forma part d'un procés més extens i complex. El procés és lent, i precisa del coneixement dels subjectes objecte d'estudi per tal d'arribar a conèixer les seves estructures de funcionament. És per aquest motiu que no podem parlar en clau d'un pas directe d'un enfocament ètic a un enfocament èmic; sinó que per passar de l'un a l'altre hi ha tot un seguit de passos intermitjos. I és aquí on recau la força de la dicotomia d'enfocaments ètic/èmic, en el que succeeix en els estadis mitjans dels dos moments: inicial i final.

\section{Estranyament i ruptures durant el procés d'investigació}

Per Michael Agar (2008 [1982]), la comprensió etnogràfica és fer evidents aquells comportaments inicialment incomprensibles. Així, els conceptes claus d'Agar són la ruptura o quiebra i els esquemes corregibles (González Echevarría 2000).

[La ruptura o] quiebra, és definida com una falta de concordancia entre el encuentro de uno con una tradición y las expectativas contenidas en los esquemas mediante los cuales uno organiza la propia experiencia. Uno modifica entonces los esquemas, o construye otros nuevos, e intenta otra vez. Basado en ese nuevo intento se realizan modificaciones adicionales, y el proceso continúa iterativamente hasta que la quiebra no es más un problema (Agar 2008 [1982]: 124). [Aquest darrer procés és el que s'anomena esquema corregible].

El procés de recerca dut a terme per Roberto Malighetti (2004) a la comunitat quilombola de Frechal (Brasil), ens servirà per il-lustrar de manera pràctica, com dur a terme el procés d'investigació a partir de la proposta que en fa Agar (2008 [1982]).

Malighetti escriu a la seva monografia que, "seguint l'exemple de Dweyer (1982), vaig decidir anar a Frechal sense un tema prefixat i específic. En aquest sentit, no 


\section{perifèria}

Número 16, junio 2012

revistes.uab.cat/periferia - www.periferia.name

havia elegit Frechal per provar una hipòtesi meva. El contrari, tenia la intenció de formular una hipòtesis durant el transcurs del procés de recerca" (2004: 18).

El seu punt de partida intentava ser neutre, sense preconceptes. Amb tot, només arribar a Frechal, ja expressa contradiccions i certs canvis d'opinions.

Ricordo che, entrato in Frechal, rimasi abbastanza colpito dal fatto di non trovare il villaggio isolato all'interno della fitta foresta tropicale dove immaginavo dovesse essere la sede più opportuna per un quilombo. Al contrario, la comunità era puttusto vicina alla cittadina di Mirinzal e confinava con l'unica strada asfaltata di recente costruzione, che attraversava la Baixada Maranhense Occidentale ${ }^{5}$ (2004: 15).

Podem dir que la quiebra assenyala la diferència entre dos mons, i que es produeix quan hi ha una disjunció entre el món de l'etnògraf i el món estudiat. Quan alguna cosa que l'etnògraf constata, trenca les seves expectatives (González Echevarría 2000: 469).

Non riuscivo a ristablirmi dall'apprensione causata da ciò che chiamavo la "sindrome della trubù noiosa" [...] mi pareva che il villaggio di Frechal no si prestasse ai "miti di fondazione dell'antropologia". [...] La disposizione delle tapias non seguiva alcun ordine particolare. La divisione del lavoro era elementare, per sesso, per età, per scambio reciproco della manodopera. La cultura materiale era molto povera. Non c'erano divisioni interne al villaggio, o un sistema di parentela ben strutturato. Le feste erano poche e povere. [...] Le credenze negli spiriti dei trapassati e in esseri di varia natura, come anche la sapienza magica

\footnotetext{
5 "Recordo que, una vegada a Frechal, vaig quedar bastant sorprès pel fet de no trobar el poblet isolat a I'interior de l'espessa selva tropical, on imaginava, havia de trobar-se el lloc més oportú per haver-hi un quilombo. Ans al contrari, la comunitat era bastant a prop de la ciutat de Miranzal i limitava amb l'únic carrer asfaltat, de recent construcció, que creuava la Baixada Maranhense Occidental."
} 


\section{perifèria}

Número 16, junio 2012

\section{revistes.uab.cat/periferia - www.periferia.name}

e la medicina popolare, non erano istituzionalizzati e ritualizzati ${ }^{6}$. (Malighetti 2004: 43).

L'esquema corregible, són els intents de comprensió dirigits a resoldre les quiebras. Per tal de superar aquesta disjunció, la quiebra exigeix la correcció dels esquemes de l'etnògraf, que ha d'entendre el comportament dels actors, i en endavant, incloure aquest tipus de comportament en els seus esquemes (González Echevarría 2000: 469). Aquest procés de comprensió es duu a terme mitjançant un procés dialèctic de preguntes i respostes entre l'investigador i els interlocutors. I a partir del qual es modifica la seva tradició, i es crea la seva visió del que és el fenomen.

Preoccupato per questa situazione, cercavo una spiegazione sia dentro sia fuori Frechal. Denis Lacabane, una fazendeiro francese che diceva di essere stato propietario della fazenda di Frechal per un breve periodo, sosteneva che nella comunità non vi fosse nulla di particolare in termini di manifestazioni culturali o altro ${ }^{7}$ (2004: 44).

Per parte loro, le persones di Frechal rimandavano un'immagine di un'epoca ormai remota e lontana, ricca di feste e manifestazioni culturali, tramontata a causa della lotta contro il fazendeiro ${ }^{8}$ (2004: 44).

\footnotetext{
6 "No aconseguia restablir-me de I'aprensió causada d'això que anomenava el síndrome de la "tribu avorrida" [...] em semblava que el poble de Frechal no es prestava als "mites fundacionals de I'antropologia". [...] La disposició de les taipas no seguia cap ordre en particular. La divisió del treball era elemental, per sexe, per edat, per intercanvi recíproc de mà d'obra. La cultura material era molt pobre. No hi havia divisions internes al poble, o un sistema de parentela ben estructurat. Les festes eren poques i pobres. [...] Les creences amb els esperits dels morts i altres éssers de diversa natura, com també la saviesa màgica i la medicina popular, no estaven institucionalitzats ni ritualitzats."

7 "Preocupat per aquesta situació, buscava una explicació, ja fos dintre o fora de Frechal. Denis Lacabane, un fazendeiro francès que deia haver estat propietari de la fazenda de Frechal durant un breu període, sostenia que a la comunitat no hi havia res de particular en termes de manifestacions culturals o d'altres."

8 "Per la seva banda, les persones de Frechal recordaven un imaginari d'una època ara ja remota i Ilunyana, rica de festes i manifestacions culturals, desapareguda a causa de la lluita contra el fazendeiro.
} 


\section{perifèria}

Número 16, junio 2012

\section{revistes.uab.cat/periferia - www.periferia.name}

La comprensió de les quiebras, continua fins a la resolució total d'aquestes. Resolució que, segons Agar (2008 [1982]: 124), es produirà quan I'horitzó de les diferents tradicions resulti "fos".

La cosa che più mi sorprendeva era che le forme culturali non corrispondevano a quello che mi aspettavo da una comunità di origine africana. I membri del villaggio praticavano in modo molto intenso ciò che si può definire un cattolicesimo popolare. Mi colpiva l'assenza di ogni culto afro-brasiliano [...] I motivi di ciò erano spiegati, con molte reticenze, dai miei interlocutori ricorrendo al loro cristianesimo ${ }^{9}$ (2004: 46).

Ero portato a interpretare questa "semplicità culturale" come un doloroso retaggio della schiavitù. [...] Appoggiandomi alla letteratura, ritenevo che gli schiavi, entrati a fare parte del contesto nazionale privi di una propria storia, una propia lingua e una propria cultura, non avessero potuto fare altro che partecipare al processo di rimozione del passato che li aveva discriminati e che continuava a farlo. Una delle principali strategie della schiavitù fu, infatti, l'annullamento dell'identità delle sue vittime. [...] Le sue politiche prevedevano la divisione e la dispersione di uno stesso gruppo come precauzione contro le insurrezioni, omologando la loro diversità culturale in categorie generiche. [...] In quest'opera di omogeneizzazione qualsiasi manifestazione della cultura religiosa o secolare degli schiavi era proibita $^{10}$ (Malighetti 2004: 48).

\footnotetext{
9 "El que més em sorprenia era que les formes culturals no corresponien a allò que m'esperava d'una comunitat d'origen Africà. Els membres del poblat practicaven de manera molt intensa, això que pot definir-se com a catolicisme popular. Em sobtava I'absència de culte afro-brasiler [...] Els motius d'això eren explicats, amb moltes reticències, pels meus interlocutors recorrent al seu cristianisme."

10 "Era portat a interpretar aquesta "simplicitat cultural" com a un dolorós patrimoni de l'esclavitud. [...] Inclinat en la literatura, pensava que els esclaus, entrats a formar part del context nacional privats d'una pròpia història, una pròpia llengua i una pròpia cultura, no haguessin pogut fer altra cosa que participar
} 


\section{perifèria}

Número 16, junio 2012

revistes.uab.cat/periferia - www.periferia.name

Per tant, a l'exemple proposat apreciem com l'autor arriba al camp amb unes idees. Idees que no encaixen amb la realitat que veu, $i$ és en aquest moment on es produeix una quiebra. En aquest moment, l'autor parla de que el poblat no té cap característica remarcable, i que la comunitat quilombola no li resulta atractiva per investigar. Amb tot, Malighetti no s'estanca en aquest primer punt, sinó que a partir de preguntar al fazendeiro i a la gent del poblat comença a buscar resposta a les quiebras plantejades; és a dir, utilitza els esquemes corregibles, els quals mitjançant un procés dialèctic de preguntes i respostes acosten a l'investigador a la comprensió del fenomen. Finalment, i com que les respostes donades no el satisfan del tot, busca l'explicació d'altres persones, i en últim lloc, s'aproxima a la literatura que existeix sobre les costums dels descendents dels esclaus brasilers. És en aquest moment on troba una resposta convincent al que ha vist, sentit i llegit. És a dir, resol aquella quiebra inicial després de parlar amb diferents persones, pertanyents a diferents àmbits, i de consultar els arxius que parlen sobre la qüestió dels descendents dels esclaus.

Tot aquest procés és explicat per Agar de la següent manera:

Comenzamos con una quiebra, con una ruptura. Esta viola nuestras expectativas y trae a la conciencia lo que el fenómeno no es. Luego sigue un proceso dialéctico de preguntas y respuestas por medio del cual modificamos nuestra tradición y creamos nuestra versión de lo que el fenómeno es, dado nuestro punto de partida. [...] Una vez que una quiebra se resuelve, abandona nuestra atención consciente (Agar 2008 [1982]: 125).

del procés d'oblidar el passat que els havia discriminat i que continuava fent-ho. Una de les principals estratègies de l'esclavitud fou, de fet, l'anul·lament de la identitat de les seves víctimes. [...] Les seves polítiques preveien la divisió i la dispersió d'un mateix grup com a precaució contra la insurrecció, homologant la seva diversitat cultural en categories genèriques. [...] En aquesta obra d'homogeneïtzació, qualsevol manifestació de la cultura religiosa o secular dels esclaus era prohibida." 


\section{perifèria}

Número 16, junio 2012

revistes.uab.cat/periferia - www.periferia.name

Per tant, podem dir que, tal com sustenta Agar, l'etnografia és el procés d'anar de la quiebra a la coherència mitjançant la resolució (Agar 2008 [1982]: 126).

\section{A mode de conclusions}

Les propostes etnogràfiques plantejades són un exemple del procés de validació. En elles, l'autor mostra el procés que duu a terme en el camp, des de les primeres aproximacions, fins als posicionaments finals. Així mateix, en totes elles, l'autor és partícip d'un procés de canvi en els plantejaments inicials, arribant a uns plantejaments finals, després de la constatació de la incongruència dels primers. No obstant, també és important remarcar com la proposta etnogràfica plantejada té un lloc important en els exemples etnogràfics, degut a que en tots ells busquen la validació de les conclusions, i centrar l'èmfasi en les interpretacions.

De tots aquests treballs se'n desprèn que la validació és un element fonamental del treball de camp antropològic, i un moment essencial de la recerca per tal de dur a terme experiències de camp rigoroses.

\section{Bibliografia}

Agar, M. (2008 [1982]), "Hacia un lenguaje etnográfico", en C. Reynoso, ed. El surgimiento de la antropología postmoderna. Barcelona: Gedisa. 117-137.

Atienza, J; Blanco, J.R. i Iranzo, J.M. (1994). "Ludwik Fleck y los olvidos de la sociología". Revista Española de Investigaciones Sociológicas 67: 243-250.

Bohannan, L. (1993[1966]). "Shakespeare en la selva", en H. Velasco, comp. Lecturas de antropología social y cultural. La cultura y las culturas. Madrid: UNED. 83-93.

Bohannon, P; i Skoggard, I. (1997)."Tiv". eHRAF World Cultures. [consultat, 5 de 


\section{perifèria}

Número 16, junio 2012

revistes.uab.cat/periferia - www.periferia.name

desembre 2011, <http://ehrafworldcultures.yale.edu>]

Dweyer, K. (1982). Moroccan Dialogues: Anthropology in Question. Baltimore: The Johns Hopkins.

Eisenhart, M. (2001). "Educational Ethnography Past, Present, And Future: Ideas to Think With". Educational Researcher 30 (8): 16-27.

Fleck, L. (1986 [1935]). La génesis y el desarrollo de un hecho científico. Madrid: Alianza Editorial.

González Echevarría, A. (2000). Tesis para una crítica de la singularidad cultural. Bellaterra: Universitat Autònoma de Barcelona - Servei de Publicacions.

(2003) Crítica de la singularidad cultural. Barcelona: Anthropos Universidad Autónoma Metropolitana Iztapalapa.

(2006). "Etnografía, brujería y tensión social: Las tribulaciones de Marwick para poner a prueba la tesis obstétrica matrilineal". Perifèria. Revista de recerca $i$ formació en antropologia 5: 1-19.

(2009a). "Del enfoque emic a los procedimientos críticos de interpretación. Retrospectiva y anticipaciones". Papeles de trabajo - Centro de Estudios Interdisciplinarios en Etnolingüística y Antropología Socio-Cultural 18. [consultat el 26 de novembre 2011, < http://www.scielo.org.ar>].

(2009b). La dicotomía emic/etic. Historia de una confusión. Barcelona: Anthropos.

Hammersley, M; i Atkinson, P. (1994 [1983]) Etnografía. Métodos de investigación. Barcelona: Paidós.

Harris, M. (2005 [1968]) El desarrollo de la teoría antropológica. Una historia de las teorías de la cultura. Madrid: Siglo XXI.

Helo, A. (1989). "Ludwick Fleck: La génesis y el desarrollo de un hecho científico". Revista de filosofía 2 (època III): 183-185.

Malighetti, R. (2004). Il Quilombo di Frechal. Identità e lavoro sul campo in una 


\section{perifèria}

Número 16, junio 2012

revistes.uab.cat/periferia - www.periferia.name

comunità brasiliana di discendenti di schiavi. Milano: Raffaello Cortina Editore.

Pike, K. (1971 [1954]). Language in relation to a unified theory of the structure of human behaviour. Den Haag: Mouton.

Roigé, X; Estrada, F; i Beltrán, O. (1999). Tècniques d'investigació en antropologia social. Barcelona: Edicions de la Universitat de Barcelona.

San Román, T. (1984). "Sobre I'objecte i el mètode de I'antropologia". Quaderns de I'Institut Català d'Antropologia 5: 122-133.

(2009). "Sobre la investigación etnográfica". Revista de Antropología Social 18: $235-260$.

Wolcott, H. (2004 [1966]). A scuola in un villaggio Kwakiutl. Padova: Imprimitur Editrice.

(2005 [1974]). "El maestro como enemigo", en H. Velasco; F.J. García Castaño; i Á. Díaz de Rada, eds. Lecturas de antropología para educadores. El ámbito de la antropología de la educación y de la etnografía escolar. Madrid: Editorial Trotta. 243-258. 